\title{
Fire, Colour, Sound and Light Chemistry Show, ETH Hönggerberg, 17. Dec. 2006
}

\author{
Gillian Harvey*
}

\begin{abstract}
As part of the ETH Zürich project 'Treffpunkt Science City' aimed at making the ETH Hönggerberg more visible and accessible to the general public, Wolfram Uhlig and Bruno Rüttimann of the Laboratory of Inorganic Chemistry presented their chemistry show entitled 'Fire, Colour, Sound and Light' to an enthusiastic audience.
\end{abstract}

Keywords: Chemistry show · ETH Hönggerberg

On the last Sunday before Christmas, 17. December 2006, Wolfram Uhlig and Bruno Rüttimann from the Laboratory of Inorganic Chemistry presented an attractive and fun chemistry show for a general audience of all ages and background entitled 'Fire, Colour, Sound and Light'.

The show was part of the ETH's 'Treffpunkt Science City', a project designed to raise the visibility and accessibility of the ETH Hönggerberg with a range of events on Sundays in November to February. The project has proven very popular with more than 2600 visitors in November and December 2006 alone.

The chemistry show was the biggest attraction with the two shows before Christmas booked out far in advance and was therefore repeated in January.

Those who were lucky enough to get a ticket arrived early to find a seat with the best possible view and were rewarded with the stage already setup with a weird and wonderful mixture of everyday items and laboratory equipment. The audience packing the lecture hall consisted of families with young children, older couples and people of every age in between.

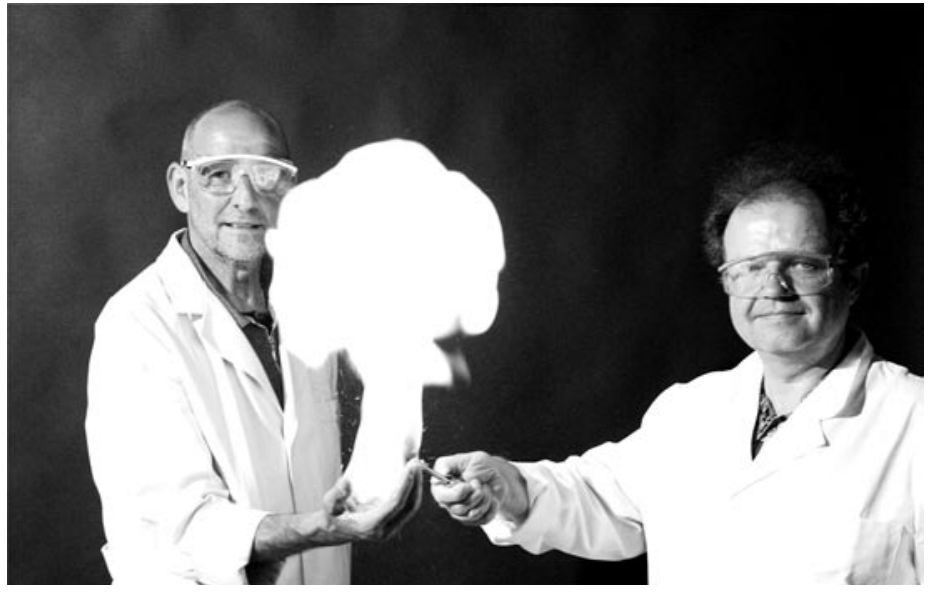

The show got underway with Wolfram Uhlig explaining that he and his partner would demonstrate experiments from three centuries of experimental science but that any explanations about the chemistry behind the effects could be found on the website www.cci.ethz.ch, the 'Creative Chemistry on the Internet' project of Prof R. Nesper.

They then swung into action with a very well practised and choreographed show that has obviously been refined and improved over many years with commentary from Dr. Uhlig and frequent comical asides from Bruno Rüttimann.

The first experiment was an iron complex solution that changed colour from brown, through green, blue, violet and back to brown and continued to do so throughout the show, followed by an example of a fast reaction, detonation of an oxygen-hydrogen mixture that involved shooting a tennis ball out of a glass tube (at a picture of a sparrow). The first experiments captured the attention of the audience effortlessly either by a reminder that chemistry does smell sometimes (an aspect strangely missing from the title) or by a very loud, satisfying bang.

Then followed a demonstration of the reaction of ammonia and oxygen that only proceeds when a very hot catalyst is added with the production of lots of sparks (very much appreciated by the children in the audience) with Dr. Uhlig making the connection to catalytic converters in cars that will also not work until they reach a sufficiently high temperature. Although the show proceeded without any chemical equations and very few chemical explanations were given, there was sufficient information for members of the audience without a scientific background to relate what they were seeing to everyday effects.

Environmental issues were also touched upon with Dr. Uhlig holding a piece of solid carbon dioxide in his hand (don't try this at home, children!) and pointing out that this represents the amount of $\mathrm{CO}_{2}$ produced by a car travelling just one kilometre. The carbon dioxide was placed in a sodium hydroxide solution to demonstrate that a gas can be 

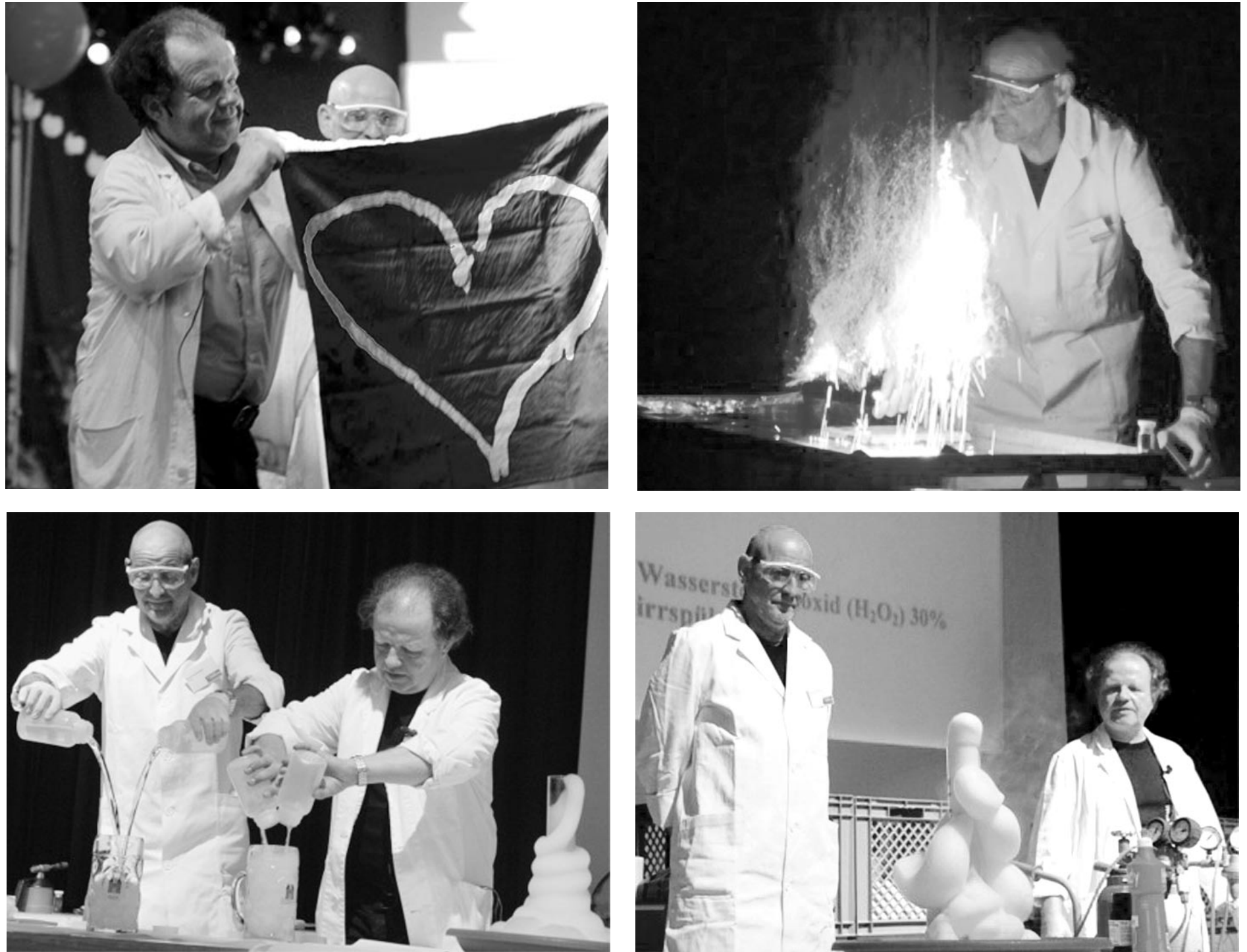

acidic and also to show what an indicator solution can be used for. Other experiments followed involving fractal colour changes with ammonia blown over the surface of an indicator solution, floating high-temperature superconductors, and a tee-shirt dyed with Congo red that changed colour when sprayed with sodium hydroxide solution.

The experiments were very well chosen for their 'wow' factor on the one hand - the very loud explosion resulting from burning $\mathrm{H}_{2}$ in a tin until enough $\mathrm{O}_{2}$ had entered to make the mixture detonate was particularly fun because there was a relatively long wait before the bang that allowed the anticipation to climb (and causing children to crawl under the benches with their fingers in their ears). On the other hand many experiments used familiar objects or effects like degassing beer with a vacuum pump to fill a very long glass tube with beer foam (Bruno Rüttimann demonstrated very good timing to disconnect the vacuum pump just before it filled with beer, probably to the relief of the chemist he borrowed it from), decomposing $\mathrm{H}_{2} \mathrm{O}_{2}$ over a catalyst in solution of washing-up liquid to produce copious amounts of soapy foam or igniting a curtain of wire wool with a battery. The demonstration of why burning oil should not be extinguished with water, which produced a fire ball almost up to the ceiling, will probably have made a lasting impression on anyone spending any time in the kitchen. For me the real star of the show (apart from Bruno Rüttimann playing the alphorn in his safety glasses as the sun set over the Hönggerberg) was the gherkin that glowed in the dark when an electric current was passed through it.

All experiments functioned perfectly thanks to the 40-years experience that Bruno Rüttimann has as a laboratory assistant, and the show was over in just 75 minutes leaving a very appreciative audience.

Given the generally negative image that chemistry has in Switzerland, the chemistry show is designed to demonstrate that science can be interesting and fun and the large audiences attracted show that people are open to persuasion. In particular the enthusiasm and interest of the large number of children in the audience showed that, despite the minimal amount of science (and even less chemistry) that is taught in Swiss schools, they are receptive to science.

The opinion of Henry, age 11: It was easy to understand, the two men knew what they were doing, I liked the experiments with the floating Samiclaus (high-temperature super conductor), the world's fastest cable car (with $\mathrm{CS}_{2}$ as propellant) and the bottles with different coloured glowing lights. I think that science is interesting and I would like to do some experiments at school. Perhaps Dr. Uhlig and Herr Rüttimann could come to our school to show us some things.

'Treffpunkt Science City' events continued during January and February with a 'A Journey through the Nanoworld'.

Received: January 9, 2007 